Scenes from Postgraduate Life

\title{
The role of clinical tutors
}

\author{
John Lister
}

Farm End, 10 Burkes Road, Beaconsfield, Bucks HP9 1PB, UK

\section{The role of clinical tutors}

In an attempt to determine the extent to which junior medical staff receive formal education and counselling, a short questionnaire was prepared and circulated to 300 clinical tutors through the National Association of Clinical Tutors (Table I).

A total of 140 clinical tutors ( $47 \%$ ) responded to this questionnaire in which they were asked to state whether they were responsible for arranging any formal educational activities for preregistration house officers (PRHOs) and senior house officers (SHOs); whether they were responsible for counselling SHOs and assessing their progress; and whether each trainee had an identified educational supervisor. They were also asked whether any protected educational time was provided in their hospital and if so, how much. Finally, they were asked to comment on any areas of postgraduate education and training in which they were experiencing problems.

Seventy per cent of respondents were responsible for arranging formal educational opportunities for PRHOs and $74 \%$ arranged such programmes for SHOs. Counselling for SHOs was provided by $85 \%$ of the tutors responding, $50 \%$ undertook some assessment of their progress and the great majority of trainees $(85 \%)$ had identified educational supervisors.

Protected educational time was only provided in $59 \%$ of the hospitals concerned and the time available was limited and variable. One described the protected time available as 'little and patchy', another stating that its provision often varied between specialties and with the grade of the trainee. Others commented that service requirements still take priority over protected teaching time although one tutor proclaimed satisfaction at having secured one hour's 'bleepless' teaching time each week.

Eighty clinical tutors made pertinent comments on other problems causing them concern. The

Correspondence: J. Lister, M.D., F.R.C.P.

This article is based on a paper presented at the Winter Meeting of the National Association of Clinical Tutors held on 27 November 1992. problem most frequently cited was the difficulty of reconciling service requirements with training needs and of finding the time for trainers to teach 3 . and for trainees to be taught. Service requirementso nearly always took priority over teaching and ${ }_{\infty}^{\circ}$ many consultants carrying heavy clinical loads $\vec{A}$ were reluctant to release their juniors for teachingos sessions. Furthermore, although most consultants $\oplus$ were keen to teach and most juniors were keen to응 learn, clinical tutors had noted a lack of commit- ment on the part of some consultants, and some? juniors did not attend teaching activities arranged을 for them, even during protected educational time. $\stackrel{\oplus}{?}$

The role of educational supervisors was another $\overrightarrow{0}$ matter for concern. Thus, although $85 \%$ of trainese had nominated supervisors, they were not alwa 3 . very active and one tutor commented that the tifeo may be conferred, but the responsibility was often not shouldered.

A total of $85 \%$ of tutors also claimed to have $\frac{\approx}{\mathbb{Q}}$ undertaken counselling for SHOs but several admitted that the standard of career counselling $\overrightarrow{\vec{O}}$ was variable, that records were not always kept and 3 some were even sceptical about the value of this activity.

Many tutors emphasized that the attitude of hospital management was crucial. In some cases managerial expectations relating to performance 3 were eroding educational time, the current ethos being more concerned with management and $\frac{O}{3}$ politics than with patient care and education. Thus education and training tend to be given a low priority by managers. On the other hand, some $\frac{}{2}$ tutors had noted an improvement since the introduction of the National Health Service reforms in $N$ 1991 and hoped that managers including those in $N$ NHS Trust hospitals could be persuaded to place ${ }_{N}$ the needs of education and training higher on their ${ }^{\omega}$ agenda.

Other issues mentioned were the relationship between medical audit and training, the preoccupa- $\frac{\Phi}{\infty}$ tion of trainees with examinations, the diversity of ${ }^{+}$ the SHO grade making appropriate structured $\frac{0}{0}$ training difficult and the need for teachers to learn $\underset{\mathbb{D}}{\stackrel{\mathrm{P}}{\mathrm{P}}}$

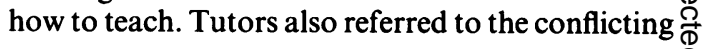


Table I Responses from 140 clinical tutors

\begin{tabular}{lrc}
\hline & \multicolumn{1}{c}{ Yes } & No \\
\hline Formal educational activities & & \\
$\quad$ Preregistration house officers & $98(70 \%)$ & $42(30 \%)$ \\
Senior house officers & $104(74 \%)$ & $36(26 \%)$ \\
Counselling SHOs & $119(85 \%)$ & $21(15 \%)$ \\
Assessing SHOs & $70(50 \%)$ & $70(50 \%)$ \\
Identified educational supervisors & $119(85 \%)$ & $21(15 \%)$ \\
Protected teaching time & $83(59 \%)$ & $57(41 \%)$ \\
\hline
\end{tabular}

demands on the time of consultants including requirements to participate in medical audit and management and sometimes to accept responsibilities in their own colleges. Staff changes resulting from the implementation of the recommendations in Achieving a Balance and the new duty rotas, following the reduction in the junior doctors' hours of work were other complicating factors. One tutor commented that his problems were almost too numerous to mention, but the central theme of the responding tutors was perhaps encapsulated in the succinct comment of one tutor who summarized his problems as 'getting time for the juniors to be taught, getting some consultants to teach and getting some supervisors to supervise'.

In view of other data - suggesting that there is little provision of formal educational activities for junior hospital staff ${ }^{1}-$ it is perhaps surprising that so many respondents claimed to be responsible for arranging such activities. On the other hand, it has previously been shown that the perceptions of those delivering instruction and those receiving it may be markedly different ${ }^{2-4}$ and of course the response rate was less than $50 \%$ so that the responsibilities of the non-responders are not known. Subsidiary questions might have elicited more detailed information, but even if some respondents may have answered too favourably there does appear to be some form of educational structure in many districts.

This reflects great credit on clinical tutors who have achieved so much in spite of considerable difficulties, but their achievement still falls short of what is required to meet the real educational needs of trainees. Indeed, it may be questioned whether it is possible to provide the structured training considered desirable within the context of the present career structure and staffing of the NHS and alternative models of graduate medical education such as those in North America might need to be considered.

\section{References}

1. Standing Committee on Postgraduate Medical Education. Formal Opportunities in Postgraduate Medical Education for Hospital Doctors in Training. London, 1992.

2. Dowling, S. \& Barrett, S. Doctors in the Making. The Experience of the Preregistration Year. School for Advanced Urban Studies, Bristol, 1991.

3. Grant, J. Senior House Officer Training in South East Thames Region. British Postgraduate Medical Federation, London, 1988.

4. Smith, R. Medical education and the GMC. Controlled or stifled? Br Med J 1989, 298: 1372-1375. 